\title{
A LEGITIMIDADE DE PROFESSORES NA EDUCAÇÃO EM EMPREENDEDORISMO: O QUE PODEMOS APRENDER DE UMA RẺVISÃO DE LITERATURA
}

\author{
Stéphane Foliard 1 \\ Sandrine Le Pontois ${ }^{2}$ \\ Alain Fayolle ${ }^{3}$ \\ Isabell Diermann ${ }^{4}$
}

\section{RESUMO}

Objetivo: Usando uma perspectiva multidisciplinar, este artigo objetiva tratar da questão da legitimidade percebida pelos PEs a partir de uma revisão de literatura que cobre todas as áreas de estudo que mostraram algum interesse pela noção de legitimidade de professores.

Método: Buscou-se os mais relevantes artigos lidando com o conceito, sem focar em qualquer campo particular de pesquisa. Optou-se por usar a base de dados Web of Science. 24 artigos permitiram investigar o tema da legitimidade de professores em empreendedorismo ou em outros campos.

Originalidade/Relevância: Os professores de empreendedorismo (PEs) evoluem em um ambiente em que diferentes categorias de pessoas interagem, assumindo uma ou mais identidades ou papéis, (até mesmo "transmissores" 5 ), da educação em empreendedorismo (EE). A relevância deste estudo se dá justamente porque a questão do reconhecimento do status profissional dos professores não é sempre abordada.

Resultados: Os PEs podem ser pessoas da prática, professores e pesquisadores. Seu grau de expertise, sua posição na instituição, sua posição em relação a outros atores e o discurso que usam são os elementos que constituem sua legitimidade. Definitivamente, a legitimidade da EE depende das interações entre instrutores legitimados e estudantes legitimados em um dado contexto que respeita certas normas coletivamente aceitas. Ela também depende do contexto e do objetivo da EE.

Contribuições teóricas/metodológicas: A legitimidade, pensada apenas do ponto de vista das relações bilaterais de cada um dos atores, é difícil de ser obtida porque falta a percepção do todo do que é oferecido pela EE. Ver o todo implica avançar para uma dinâmica de relações multilaterais no contexto da EE e em um prazo preciso, o prazo dos atores-chave: os estudantes. Enquanto a EE pode ser uma área de estudo e um campo de conhecimentos emergentes, os fatores sociais e econômicos ligados ao empreendedorismo justificam o uso do melhor processo possível de profissionalização para os PEs.

Palavras-chave: Legitimidade e Professores; Professor de Empreendedorismo; Educação em Empreendedorismo.

\author{
Received on: 06/07/2019 / Approved on: 04/12/2019 \\ Responsible editor: Profa. Dra. Vânia Maria Nassif \\ Translator: Edmilson de Oliveira Lima \\ Evaluation process: Double Blind Review \\ Doi: http://dx.doi.org/10.14211/regepe.v9i1.1804
}

\footnotetext{
1Jean Monnet University -Saint-Étienne (França) E-mail:stephane.foliard@univ-st-etienne.fr Orcid: https://orcid.org/0000-0003-4424-8756

2Jean Monnet University -Saint-Étienne (França) E-mail:editorialregep@gmail.com Orcid: https://orcid.org/0000-0002-0725-9379

${ }^{3}$ Emlyon Business School - Écully (França) E-mail:alain.fayolle@esisar.inpg.fr Orcid: https://orcid.org/0000-0002-6092-6898

${ }^{4}$ University of Kassel - Kassel (Alemanha) E-mail:editorialregep@gmail.com

** Este artigo foi originalmente publicado: Creating Entrepreneurial Space: Talking through Multi-voices, Reflections on Emerging Debates Contemporary Issues in Entrepreneurship Research, Volume 9A, 7-23 - Copyright (C 2019 by Emerald Publishing Limited - All rights of reproduction in any form reserved - ISSN: 2040-7246/doi:10.1108/S204072462018000009A001. Traduzido com a permissão da editora e do autor.
}

1 Os PE são "transmissores" no sentido de que eles traduzem o ambiente para sequências pedagógicas (Fayolle, Verzat, \& Wapshott, 2016). Eles definem o tempo, a regularidade, o conteúdo e os métodos (Ruskovaara, \& Pihkala, 2015). 


\section{INTRODUÇÃO}

Desde que a primeira disciplina oficial de empreendedorismo foi oferecida a estudantes na Universidade de Harvard em 1947, os programas de educação em empreendedorismo (EE) têm crescido continuamente (Katz, 2003) e agora encontram-se sob intensas pressões social e política (sob as diretivas da União Europeia). Ao mesmo tempo, a EE tem progressivamente se tornado um destacado tema e campo de pesquisa. Uma das consequências da riqueza da literatura científica no campo da EE é a emergência de um alto nível de reflexão sobre O quê? Como? Por quê? do ensino do empreendedorismo (Fayolle, 2013), principalmente por parte dos pesquisadores e dos criadores de políticas públicas.

Os professores de empreendedorismo (PEs) evoluem em um contexto no qual diferentes categorias de pessoas interagem: estudantes, professores, stakeholders (internos e externos às instituições), pesquisadores acadêmicos e pares (outros PEs). Quando se fala de PE, refere-se a professores do tema empreendedorismo, professores-pesquisadores e professores-empreendedores. Como a relação entre jovens e figuras de autoridade tem mudado ao longo das últimas décadas, a legitimidade deve agora ser conquistada e não é garantida pelo simples fato de um professor trabalhar para uma instituição (Graça, Calheiros, \& Barata, 2013; Hirschkorn, 2006). Além disso, a questão do reconhecimento do status profissional dos professores nem sempre é abordada (Hargreaves, 2000).

Assumindo uma ou mais identidades ou papéis, os professores, pessoas da prática, ex-empreendedores e/ou pesquisadores, são os "transmissores"6 da EE. Evoluem em um ambiente em que diferentes tipos de atores têm variadas expectativas quanto à legitimidade e isso gera tensão para os três pilares da EE: ensino, pesquisa e prática. Na educação superior, Katz (2008) identifica três estágios na construção dos programas de ensino em empreendedorismo: realização de aulas tradicionais, contribuições de profissionais com/ou profissionalização de professores e o desenvolvimento da pesquisa acadêmica sobre a EE. Entretanto, é possível notar que falta um quarto estágio: fazendo avançar a pesquisa prévia, a legitimidade dos PEs deve ser estabelecida para apoiar um setor de EE que seja construído sobre sólidos fundamentos teóricos e

2 Os PEs são "transmissores" no sentido de que eles traduzem o ambiente para sequências pedagógicas (Fayolle, Verzat, \& Wapshott, 2016). Eles definem o tempo, a regularidade, o conteúdo e os métodos (Ruskovaara, \& Pihkala, 2015). 
metodológicos (Fayolle, 2013) e faça com que seja dado apoio para o desenvolvimento profissional dos PEs.

De fato, a pesquisa científica sobre a EE apresenta fraquezas (Byrne et al., 2014; Fayolle, 2013), notadamente a falta de interesse por temas como: 1) a legitimidade percebida dos PE; e 2) o apoio que eles recebem na realização de seu trabalho (particularmente quanto ao desenvolvimento profissional). $O$ tema da legitimidade percebida dos PEs mal tem sido abordado, o que justifica a necessidade de olhar mais de perto outras áreas de estudo para melhor explorar o tema.

Usando uma perspectiva decididamente multidisciplinar, este artigo objetiva tratar da questão da legitimidade percebida de PE a partir de uma revisão de literatura que cobre todas as áreas de estudo que mostraram algum interesse pela noção de legitimidade do professor. Nesse sentido, inicialmente é apresentado um levantamento da literatura sobre a legitimidade de instrutores, tanto na EE quanto em outros campos. Na sequência, é analisado o papel de "transmissor" assumido pelo PE, que atua em um ambiente complexo e ambíguo que precisa ser analisado e compreendido (Toutain, Fayolle, Pittaway, \& Politis, 2017). Dando continuidade, discute-se o desenvolvimento profissional como uma alavanca a permitir aos PEs tornarem-se experts legítimos aos olhos de diferentes atores da EE e como parte de uma equipe. Por último, são sugeridas algumas linhas de pesquisa que podem ampliar a compreensão da legitimidade de professores no campo do empreendedorismo.

\section{LEGITIMIDADE DOS PROFESSORES: CONTRIBUIÇÕES DE UMA REVISÃO DE LITERATURA}

A legitimidade resulta de um processo de legitimação, que significa a ação de conformação a padrões, atitudes e modelos estabelecidos para comportamento (Collins Dictionary, 2017). Fala-se aqui de um construto social e multidimensional complexo (Tyler, \& Lind, 1992) que é baseado em um processo cognitivo envolvendo subjetividade e viés intrínsecos. Portanto, a legitimidade integra a qualidade de relações em julgamentos que se fazem. Ela é negociada "de momento a momento" e pode depender do contexto, dos atores envolvidos e das expectativas destes (Creese, Blackledge, \& Takhi, 2014). A estratégia de 
legitimação ocorre no discurso para construir sentido e define o que é ou não legitimado (Lindströma, 2016). Este artigo trata da legitimidade percebida pelos PEs segundo a perspectiva de todos os atores envolvidos.

\subsection{Metodologia}

Para contextualizar a legitimidade de professores no campo do empreendedorismo e, mais especificamente na EE, buscou-se os mais relevantes artigos lidando com o conceito, sem focar em qualquer campo particular de pesquisa. Optou-se por usar a base de dados Web of Science. Os principais critérios de seleção de artigos dessa base consistiram em fazer buscas com combinações de palavras-chave e sua ocorrência em títulos e resumos de artigos (TI e TS): "entrepren*", "educat", "train"”, "coach"”, "professional"”, "expert"” e "legitim*". Os artigos contendo implicações ou recomendações para a EE foram incluídos na seleção. De modo similar, os artigos que não pareceram relevantes foram sistematicamente excluídos (aqueles relativos a trens - trains, em Inglês).

Uma vez identificados os artigos mais relevantes, fez-se referência cruzada dos títulos e resumos de cada um para confirmar ou rejeitar sua pertinência para esta pesquisa sobre legitimidade percebida pelos PEs (artigos relativos a EE ou com sugestões transferíveis para a EE), tentando em particular identificar os construtos usados por pesquisadores em outros campos. Dado que o tema - a legitimidade de PE - foi raramente estudado na literatura prévia, foi decidido usar a abordagem mais inclusiva possível. A razão disso é que, mesmo que o fator de impacto de cada revista acadêmica fosse tomado como um importante critério na seleção (critérios de reputação), não foi usado exclusivamente (critérios de saturação teórica).

Concluiu-se a primeira fase de construção de revisão de literatura acumulando artigos que pareceram ser chave, por estarem citados em diferentes outros artigos ou que enfatizaram fortemente sugestões que esses mesmos artigos fizeram.

Por fim, foram selecionados 20 artigos dos 27 coletados na Web of Science e quatro outros foram acrescentados, pois foram citados repetidamente ou clareavam de modo relevante ideias do primeiro grupo de artigos. Portanto, 24 artigos permitiram investigar o tema da legitimidade de professores em 
empreendedorismo ou em outros campos. Os campos relacionados com esses artigos retidos acabaram sendo: empreendedorismo, EE, educação e treinamento (também no campo do esporte), sociologia, psicologia e medicina.

\subsection{Explorando o Tema da Legitimidade do Professor}

\subsubsection{No empreendedorismo}

Mesmo que o campo de estudo do empreendedorismo ainda possa não ser completamente reconhecido por outros campos (Katz, 2003; Kuratko, 2005), de um ponto de vista político, ele o é. Buscando sua própria legitimidade (Fayolle et al., 2016), a EE entrou na fase de legitimação (Maritz, 2017), ou até mesmo já atingiu a legitimidade (Gibb, 2011), tendo se tornado "um campo completamente legitimado, mas ainda sem maturidade", segundo Katz (2008). Não obstante, a cultura das instituições de ensino está frequentemente em oposição à cultura do empreendedorismo, levantando assim a questão da legitimidade da EE. Em todas as áreas de estudo, o simples fato de se oferecerem programas de formação, conduzirem pesquisas sobre um tema e comunicarem conhecimentos novos define o que é legítimo para se ensinar ou pesquisar (Gibb, 2011). Vários fatores dão sustentação à legitimidade dos PEs:

a) Históricos, treinamento e experiência do mundo real: Integrada no mundo real (Fayolle, 2013; Neck, \& Greene, 2011; Solomon, 2007), a EE cumpre o papel de conectar estudantes a empreendedores atuando como mentores e modelos inspiradores por meio do ensino (Katz, 2008; Ruskovaara, \& Pihkala, 2015; Solomon, 2007). O papel dos professores está evoluindo, eles estão se tornando operadores, decisores centrais e facilitadores. Um risco então surge: se os empreendedores têm legitimidade quando ensinam, como pessoas que aportam elementos culturais para representarem a comunidade de empreendedores, então professores que não são empreendedores podem não ser legitimados, dado que ser apenas professor pode ser visto como insuficiente e então não legitimado. Ruskovaara e Pihkala (2015) lembram que há pouca informação geral disponível sobre o histórico dos PEs. O desafio para os professores é o de apresentar a EE como um constituinte-chave da universidade empreendedora, assim envolvendo 
todos os atores, inclusive professores que ensinam conteúdos de modos tradicionais. Os dois pesquisadores fazem numerosas sugestões, incluindo que quanto mais experiências profissionais da vida real em negócios os professores tiverem, mais capazes serão para liderarem um programa de EE, isto é, quanto mais experiência profissional os professores têm, mais inclinados serão para serem líderes na EE. Finalmente, o treinamento relativo a negócios para professores, afeta de modo positivo as práticas de EE dos professores ${ }^{7}$. Portanto, a legitimidade percebida pelos PEs em si depende das relações deles com o mundo dos negócios, do período de tempo em que eles estiverem envolvidos na esfera profissional e da qualidade do treinamento recebido para oferecerem à EE. Os PEs ganham sua legitimidade aos olhos de outros atores mostrando-Ihes a qualidade de suas aulas para o empreendedorismo (dimensão cognitiva), sobre empreendedorismo (dimensão afetiva) e pelo empreendedorismo (dimensão conativa). A legitimidade é então construída com base na semelhança entre o que é ensinado, o que realmente é feito no mundo dos negócios (boa prática) e o nível de familiaridade dos professores com o empreendedorismo ou com a experiência de ser um empreendedor (Seikkula-Leino, Satuvuori, Ruskovaara, \& Hannula, 2015). Como o empreendedorismo está embasado nos conhecimentos tácito e explícito, a legitimidade do ensino e dos PEs vêm por via da habilidade de desenvolvimento de conhecimento em três dimensões: cognitiva, afetiva e conativa (Fayolle et al., 2016; Peltonen, 2015);

\section{b) Expertise, rede de relação e compartilhamento de informações com os}

pares: Apesar de a dimensão cognitiva ser importante, o conhecimento corrente e autêntico (conhecimento genuíno) é crucial. Assim, os PEs estão ligados a um papel central de "transmissores"8 e agentes de mudança (Gibb, 2011). Os PEs que querem desenvolver uma expertise em empreendedorismo buscam desenvolver uma rede de relações profissional com empreendedores locais e instituições ligadas ao empreendedorismo. Podem, portanto, manterem seus conhecimentos

\footnotetext{
${ }^{7}$ Esse efeito positivo do treinamento nos PEs não é, contudo, indicativo de uma amplitude das oportunidades de treinamento. Será que essa falta de acesso ao treinamento mostra uma falta de legitimidade oferecida pela instituição ou uma falta de interesse da parte dos próprios PEs pelo desenvolvimento profissional na EE? ${ }^{8}$ Maritz (2017) oferece um modelo das dimensões da EE (audiência, pedagogia, conteúdo, contextualização, acesso, objetivos, resultados e ecossistemas de empreendedorismo), mas não inclui professores na audiência nesse modelo. Mas nós consideramos tal inclusão no presente artigo, vendo os PEs como transmissores da EE.
} 
atualizados e torná-los mais autêntico, terem um discurso baseado em experiências para ganharem legitimidade, fazendo assim uma conexão no campo da EE entre programas de ensino e o contexto. A legitimidade de um professor em uma instituição também decorre de sua habilidade de mobilização de seus pares (outros professores), de aumentar o número de suas iniciativas pessoais em realização e de desenvolvê-las em suas redes de relação. Isso pode ser feito buscando-se obter um conjunto de informações que sustente a legitimidade de suas iniciativas, até mesmo se o professor não tem uma posição forte na instituição (Gibb, 2011);

c) Diálogo “centro-periferia” para o desenvolvimento de habilidades: Usando as palavras de Rae (2017), a contribuição de uma aprendizagem empreendedora diverge da abordagem educacional porque a primeira é experiencial, situacional e contextual. Por vezes, ela ocorre fora de uma instituição educativa, é mediada individual e socialmente, podendo também ser centrada na transformação de ideias e problemas em oportunidades e ações (versão traduzida aqui para o Português).

Ligada ao contexto periférico, a EE é entendida nos ambientes físico e simbólico da universidade e do mundo fora dela. Parece necessário adotar uma abordagem "fora dos muros" que permita aos PEs novatos (recém-chegados ${ }^{9}$ ) e aos novos estudantes desenvolverem as habilidades que precisarão para trabalharem entre o centro e as periferias de suas atividades profissionais e aperfeiçoarem suas redes de relação e relações em si com outros atores. Eles integram, portanto, uma comunidade de prática formal e informal legitimada que valida a ação simplesmente pelo pertencimento à comunidade, até mesmo se são novatos (conceito de "participação periférica legitimada" - Wenger, 1998).

$\mathrm{Na}$ realidade, as empresas de maior sucesso são aquelas que, além de administrarem conexões fortes, também podem desenvolver conexões frouxas com seu ambiente (Granovetter, 1983) e iniciarem jornadas de ida e volta entre seus centros e suas diferentes periferias. Uma questão central para as instituições

${ }^{9}$ Eide e Olsvik (ENRI working paper, 2017) afirmam que os recém-chegados consideram que o treinamento que recebem não os prepara adequadamente para tomarem a responsabilidade de dirigirem estudantes em um projeto empreendedor coletivo. 
de ensino é então como pôr seus estudantes, e até mesmo elas próprias, lá fora no mundo real e possibilitar-Ihes construírem suas próprias legitimidades.

A pesquisa sobre EE é uma atividade recente, ainda em busca de legitimação. O PE, um transmissor, tem o papel de traduzir a complexidade do ambiente em atividades pedagógicas. Pergunta-se: o conhecimento em empreendedorismo tem que ser autêntico para ser legitimado ou é suficiente traduzi-lo em conteúdo de ensino? Que tipos de contatos deveriam ocorrer com outros atores? (Fayolle et al., 2016). Para voltar às três formas de legitimidade identificadas por Aldrich e Fiol (1994) e citadas por Katz (2008), nota-se tensões entre a legitimidade moral (a EE opera no contexto de normas e valores sociais), legitimidade cognitiva (o nível de aceitação da EE) e a legitimidade regulatória da EE (conformidade da EE a regras e autoridade). O campo do empreendedorismo é parcialmente legitimado (Katz, 2008), mas essa nova condição ainda não foi amplamente divulgada (Gibb, 2011). O mesmo acontece com a EE e os PEs.

\subsubsection{Em outras áreas de estudo: claridade para a EE}

Sobre o desenvolvimento de comunidades de aprendizagem e da governança de gestão, percebe-se que as universidades estão praticando um isomorfismo mimético de modo que elas próprias estão (re)produzindo métodos e conhecimento. As legitimidades, profissional, política e institucional são assim construídas pela reprodução, cuja conformidade é estabelecida em relação ao passado, quanto ao que é esperado para a identidade dos atores. Por exemplo, para os professores, isso significa atividades de ensino e pesquisa, com o risco de perda de sua conexão ontológica com a prática. O reconhecimento profissional depende assim de dois eixos que estão, às vezes, em competição: desenvolver comunidades de aprendizagem para assegurar a qualidade do treinamento de professores enquanto se oferece governança às pessoas da profissão (Grimmett, Fleming, \& Trotter, 2009).

Indo além da dicotomia "autêntico-não autêntico" para impulsionar a adaptação às expectativas dos atores e do contexto com um discurso apropriado, nota-se que a questão da legitimidade dos professores é frequentemente discutida na área da aprendizagem de línguas estrangeiras, notadamente se os professores são falantes nativos ou não nativos. Para ilustrar esse ponto, associaremos o 
professor ideal, que é falante nativo (Creese et al., 2014), com o ideal professorempreendedor e o falante não nativo, com o professor não empreendedor.

Ainda usando a analogia de Creese et al. (2014), o PE que é empreendedor é o autêntico contribuidor com elementos de cultura e de empreendedorismo que Ihe permite representar a comunidade de empreendedores em uma universidade. Sua legitimidade é confirmada, por contraste, pelos $P E s$ que não são empreendedores (ou seja: os professores puramente acadêmicos), vistos como não autênticos por outros atores. Portanto, o fato de ser um empreendedor pode ser visto como um modelo ou norma para ensinar como empreender, já que o status do empreendedor inclui de fato um alto nível de competência em todos os campos do empreendedorismo, assim como ser um falante nativo quando se ensina uma língua estrangeira. É com o discurso e a experiência que tais professores se caracterizam como empreendedores e, com isso, legitimam os instrutores em empreendedorismo.

Contudo, a pesquisa demonstra que professores de língua estrangeira que não são falantes nativos podem ter melhores resultados porque eles são mais próximos dos estudantes, o que nos lembra do posicionamento de Ruskovaara e Pihkala (2015), mencionado acima. A legitimidade dos professores - em línguas assim como em empreendedorismo - pode depender do contexto e, assim, da audiência, das expectativas da audiência e do crédito que esta dará ao discurso dos professores (veja Fayolle et al., 2016). Então, se o objetivo desejado é simplesmente aumentar a consciência quanto ao empreendedorismo, talvez não seja necessário ter um empreendedor como professor se a contribuição extra dele pode parecer irrelevante para a audiência visada. Os instrutores podem ter legitimidade em suas práticas sem necessariamente serem autênticos, do mesmo modo que empreendedores sem experiência em educação não precisam ser considerados impostores ao ensinar.

Há ainda, um ato profissional em um jogo de poder institucional, no qual as universidades, como muitos outros espaços, estão no centro de desequilíbrios de poder: os professores devem fazer o que é valorizado pela instituição, que the permite ganhar legitimidade na estrutura. Eles precisam ser portadores de múltiplas experiências - capital cultural (Bourdieu, 1979) - para construírem para si uma compreensão e modos de se comportarem que Ihes pareçam profissionais. Esse capital pode então ser compartilhado e levar ao reconhecimento (ou não) de 
ações e/ou comportamentos: "'ser profissional' no que 'você faz, como você se comporta' [...] e 'ser um profissional' no modo 'como outras pessoas o consideram e como isso afeta o jeito como você considera a si mesmo'" (Hargreaves, \& Fullan, 2012, apud Nielsen, 2016 - N.T.: traduzido aqui para o Português).

Emerge assim uma necessidade: de definir o profissionalismo de professores, incluindo o conjunto de padrões claros. Realmente, a legitimidade de um ator é estabelecida quando uma clara definição de sua função já existe, assim permitindo que todos os demais atores o percebam como um profissional. $O$ profissionalismo desse professor é um critério-chave de recrutamento nas instituições, as quais, por sua vez, ganham legitimidade de modo intermediado. Três componentes estabelecem uma "profissão": "um sistema de conhecimento, a realização de trabalho especializado e um monopólio de prática que se faz cumprir legalmente" (Quirke, 2009). Ainda assim, se considerar a atividade de instruir na EE como uma profissão, isso pode levar a divergências quanto a se as decisões de recrutamento são executadas de acordo com uma estrutura de critérios de credenciamento para legitimação e não com qualidades pessoais e conhecimento tácito, considerando que este último é particularmente importante na EE.

A legitimidade institucional à legitimidade pessoal (autolegitimidade) evoca a busca que coachs fazem por legitimidade. George (2013) destaca a proatividade das iniciativas dos coachs para conquistarem legitimidade profissional, eles passam da legitimidade institucional à legitimidade pessoal. Na comparação com a $\mathrm{EE}$, os PE certamente constroem sua legitimidade não apenas a partir do status que Ihes é dado pela instituição, mas também com sua habilidade para interagir com sua audiência com profissionalismo.

Hirschkorn (2006) oferece um modelo segundo o qual questões de legitimidade emergem na interação entre a forma (conhecimento) e o contexto. A adaptação da EE a seu contexto, incluindo a forma e as habilidades desenvolvidas, é o que faz sua legitimação externa. A adaptação a seu conteúdo e ao modelo de ensino forma sua integridade interna.

A construção da legitimidade institucional pode vir dos atores envolvidos, em uma abordagem de baixo para cima, em termos hierárquicos, com grupos de participantes internos negociando, definindo e transmitindo conhecimento internamente, ou seja, em uma rede de pares. Esse processo permite às pessoas que recebem a legitimação posicionarem-se na instituição que legitima suas 
práticas (Eddy Spicer, 2013; Gibb, 2011; Rae, 2017). Mas a legitimidade institucional pode também vir de dois outros tipos de interação: entre os professores e administradores (internamente na instituição) e entre os professores e o exterior (Eddy Spicer, 2013). Desse modo, a legitimidade é construída comparando-se cada professor a outros atores.

Por um lado, o feedback do discurso dos pares e stakeholders permite que as ações de cada professor sejam legitimadas pela socialização vivida em uma relação de confiança. Por outro lado, a prática reflexiva permite aos professores afirmarem suas próprias identidades pessoais e se autolegitimarem - legitimidade percebida (Klossner, 2008). No mais, a difusão por imitação é o processo central de legitimação da (e pela) instituição, aproveitando-se o alinhamento entre o que está sendo feito e o que funcionou no passado (Pedersen, \& Dobbin, 2006). A legitimação via discurso foi regularmente evocada pelos autores identificados em nossa revisão de literatura.

Identificando reivindicações, para legitimação profissional, feitas por diferentes atores. Uma segunda analogia pode ajudar a compreender a legitimidade dos PEs: imaginar o PE como um trabalhador de hospital, possivelmente situado entre a prática (lado empreendedor), a pesquisa e o ensino (na EE). Sanders e Harrison (2008 - N.T.: traduzido aqui para o Português) identificam, nos trabalhos relacionados à saúde, quatro bases de reivindicação para legitimação profissional dos trabalhadores:

[...] "expertise especializada", para legitimar seus papéis profissionais com relação à expertise derivada da especialização no trabalho; "demonstração de competência", por exemplo, com um discurso sobre competência profissional segundo sua [própria] perspectiva; "eficiência organizacional" e "centralidade do paciente" (abordagem holística).

Essas bases de reivindicação podem ser aplicadas aos PEs, considerandose o estudante (e não um paciente de hospital) no centro do processo. Enquanto seus papéis profissionais justificam a legitimidade cientificamente falando, a EE esteve, por muito tempo, no centro de um campo de iniciativas e de inovação pedagógica pragmática, sem qualquer real sustentação teórica que contraste com a realidade. Os demais campos de ensino fizeram esse trabalho para suas áreas especializadas (ver, por exemplo, Creese et al., 2014, que tratam da legitimidade do professor em Inglês como língua estrangeira) e talvez não reconheçam a EE 
segundo os mesmos critérios.

Finalmente, a legitimidade do professor se ligará àquelas decisões tomadas ou atividades realizadas que forem favoráveis aos estudantes, à instituição e aos stakeholders internos e externos. Se os professores têm autoridade, conferida pela instituição que os recrutou, sua legitimidade é um processo cognitivo que vem da avaliação de procedimentos e processos, assim como da qualidade de suas relações - isto é, regularidade, relevância, soluções e ferramentas oferecidas, estabelecimento de uma relação de confiança e neutralidade (Tyler, \& Lind, 1992).

\subsubsection{O que a EE e outros campos têm em comum: levando-se em conta as necessidades daqueles que aprendem}

Graça et al. (2013) insistem na importância da qualidade da prática pedagógica (ou seja, alinhamento das atividades pedagógicas com as necessidades dos estudantes) como um fator que influencia as crenças e comportamentos dos estudantes, que então reconhecem a legitimidade do professor, ainda mais quando o professor lhes dá progressivamente mais autonomia.

A legitimidade dos PEs é então construída por um processo que considera as necessidades dos estudantes e demais pessoas em aprendizagem. O conjunto daqueles que aprendem deve ser respeitado segundo o grau de autonomia concedido a eles, o que eles querem, o significado que atribuem ao que fazem e a expectativa de receberem feedback que considerem satisfatório (Fayolle et al., 2016).

A legitimidade de uma disciplina ensinada também deriva da habilidade do PE em garantir a qualidade dela e ver o que ela significa em comparação com as necessidades dos estudantes (Katz, 2008). Se os PEs alinham o ensino com as necessidades dos estudantes iniciando e facilitando discussões abertas sobre as normas e valores da disciplina de empreendedorismo - por exemplo, a abordagem adotada em sala de aula - eles ganharão legitimidade ao invés de serem constantemente questionados quanto a legitimidade (Günzel-Jensen, \& Robinson, 2017). 


\section{DISCUSSÃO: COMO DESENVOLVER A LEGITIMIDADE DOS PROFESSORES EM EMPREENDEDORISMO?}

A EE é um novo campo que se situa no cruzamento dos caminhos das ciências da educação com os do empreendedorismo e, assim, envolve muitos atores com variados históricos. A questão da legitimidade não deveria ser apenas levantada quanto à interação entre o professor e cada um desses atores tomados individualmente, o que seria uma leitura simplista. Os estudantes querem aprender, desenvolverem habilidades e obterem boas notas. A instituição de ensino quer brilhar. Pares e colegas querem dar sustentação ao campo disciplinar. Os empreendedores querem ver seus parceiros se desenvolverem.

Há muitos pontos de vista a considerar. Alguém que queira trabalhar com EE deve começar por entender os variados atores e decodificar suas mensagens para integrá-los em uma abordagem inclusiva. Isso ajuda a passar do simples ao complexo e descobrir a dinâmica de propriedades novas que não são simplesmente achadas entre os componentes da EE, ou nos atores individuais ou no conhecimento na área do saber, mas nas dinâmicas, nas interações entre os próprios componentes. São essas interações que dão significado à EE por enriquecimento mútuo entre os diferentes elementos e que criam a legitimidade do professor por via das habilidades dele em integrar todos os atores na mesma iniciativa (veja a Figura 1). 


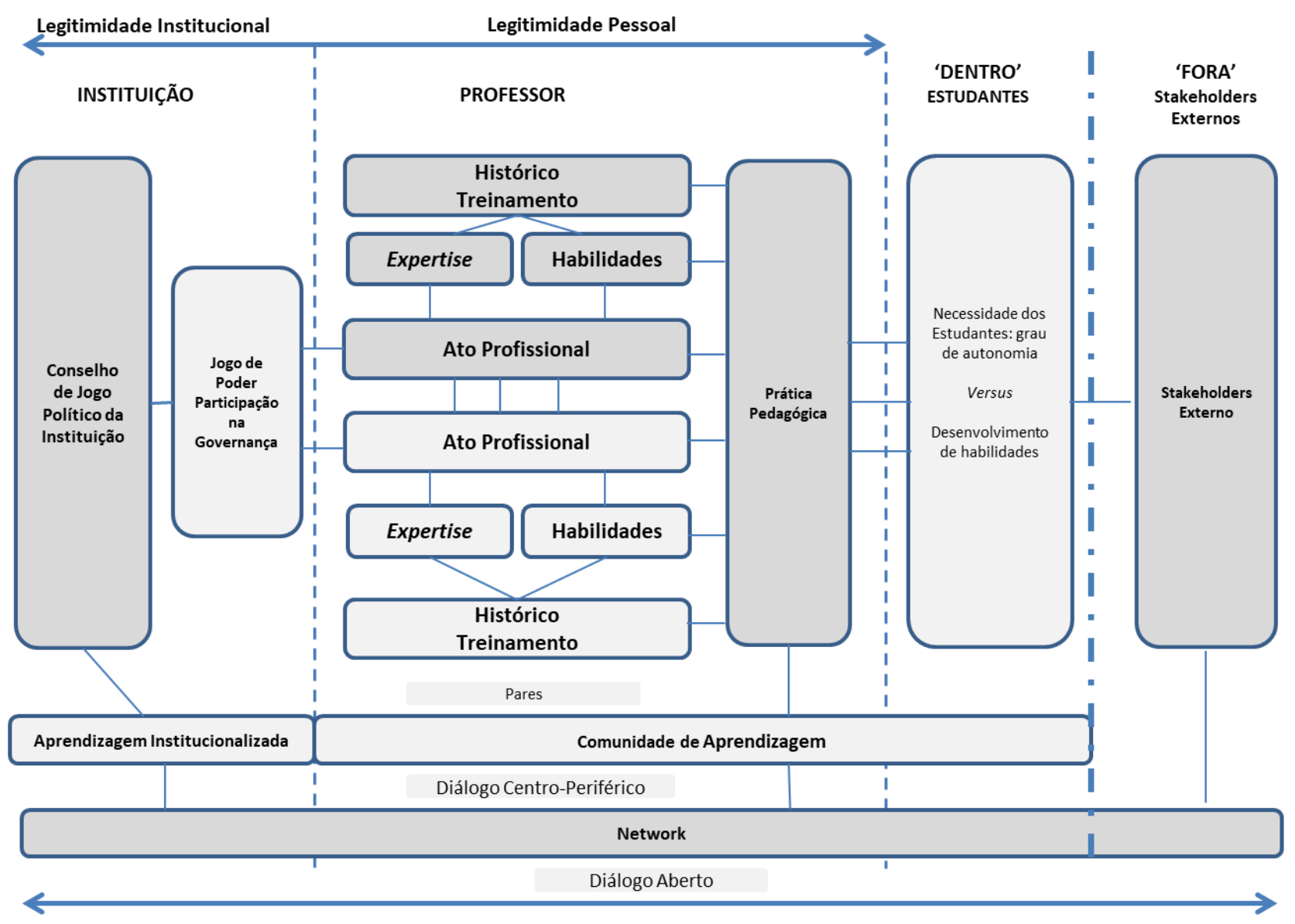

Figura 1: Vetores de legitimação para os PE

Fonte: Elaborado pelos autores (2019)

A expertise, que faz do professor alguém especial e legitimado aos olhos dos atores da EE, junta os elementos da base de todas as tensões, desafios e paradoxos potenciais. Ela é disponibilizada pelos campos do empreendedorismo, da EE e da educação. Os três campos envolvem conhecimento, práticas e iniciativas de reflexão que incluem projetos. Cada um desses pontos apenas faz sentido em um contexto socioeconômico preciso e em uma estrutura coletivamente mais ampla, desenvolvida de atividades, cursos e disciplinas oferecidos pelas instituições de ensino. O contexto inclui a cultura empreendedora e a dinâmica locais, órgãos representativos (câmaras de comércio) e a rede de associações locais, assim como autoridades locais. Tudo isso é naturalmente influenciado por expectativas ou necessidades particulares de diferentes atores. 


\subsection{Como o Desenvolvimento Professional Permite ao PE Tornar-se um Expert Legitimado a Participar de uma Equipe de Diferentes Atores em EE}

Para ser um real expert e beneficiar-se da legitimidade concedida por cada uma das partes, seria preferível para os PEs desenvolverem conhecimentos e habilidades que superem a estrutura de desenvolvimento profissional que já os ajuda (Figura 2).

a) Os PEs são experts em empreendedorismo e dominam conhecimentos específicos desse campo, as práticas do empreendedor, sua criatividade, sua cultura, sua rede de relação, como ele progride, etc;

b) Os PEs são experts em educação, tendo completado uma formação em ciências da educação. Dominam o conhecimento requerido, sentem-se confortáveis com práticas pedagógicas e também são capazes de desenvolvê-las para suas próprias necessidades ou para sua comunidade em geral, se também forem pesquisadores no campo;

c) Os PEs também são experts especificamente em EE e em suas particularidades: aprender fazendo, grupos de trabalho com estudantes de empreendedorismo, desenvolvimento de redes de relação para terem informações atualizadas e para dirigir atividades dos estudantes, realização de lobby em instituições para financiamento de projetos, etc.

\begin{tabular}{|l|c|l|l|l|l|}
\hline & & Conhecimento & Práticas & Práticas & \\
\hline \multirow{3}{*}{ Curriculum } & Empreendedorismo & & & & \multirow{2}{*}{ Contexto } \\
\cline { 2 - 5 } & EE & & & \\
\cline { 2 - 4 } & \multicolumn{2}{|c|}{ Educação } & & & \\
\hline \multicolumn{3}{|c|}{ Expectativas dos atores (estudantes, instituição, stakeholders, pares...) } \\
\hline
\end{tabular}

Figura 2: Expertise do professor da educação em empreendedorismo Fonte: Elaborado pelos autores (2019)

Encontrar um professor que corresponda às características dos três tópicos é certamente possível. Encontrar dois na mesma instituição de ensino que correspondam a elas é mais desafiador. O desenvolvimento de tal nível de expertise não é tarefa para uma pessoa trabalhando sozinha. Por isso, dois 
cenários precisam ser considerados e servirem para lembrar de um dilema do empreendedorismo: é melhor ser rei ou ser rico?

Se os professores quiserem que suas atividades sejam poderosas e efetivas, vão limitar o escopo de ação e, portanto, a legitimidade que ganharão. Contrariamente, se os professores querem enriquecer o programa de ensino, abrem o escopo de ação para seus pares e trabalham como parte de uma equipe com a expertise necessária para atender as necessidades dos stakeholders. Esse segundo cenário é evidentemente o mais relevante mesmo que requeira que os PEs consigam convencer seus pares possuidores da expertise a trabalharem junto.

Os professores devem trabalhar para reunirem uma equipe pedagógica e parecerem legitimados fazendo-o. Precisam adaptar o discurso visando promover o programa de ensino e as inovações pedagógicas que queiram desenvolver (Peltonen, 2015). É a visão como um todo que deve ser apresentada e não apenas a relação que se pode desenvolver entre o expert, os professores e os estudantes, ainda que apenas apresentar essa relação já seria útil.

\subsection{Os PEs Constroem e Consolidam sua Legitimidade com a Ação e o Discurso}

Envolvidos em programas de ensino que usam diferentes abordagens e métodos baseados em suas experiências e predominantemente nos paradigmas funcionalistas (Tedmanson, Verduyn, Essers, \& Gartner, 2012), os PEs desenham eles mesmos uma prática vívida de ensino de empreendedorismo. Essa prática funda-se na noção de ação como um processo de prática construída socialmente e emergente. Fortes tensões emergem entre expectativas de diferentes atores e como veem a legitimidade dos PEs. O posicionamento dos PEs fica então difícil.

Lindströma (2016) define quatro estratégias de legitimação ${ }^{10}$ e cinco modos de uso da linguagem para legitimar novas identidades em termos de papeis profissionais. Aplicadas à EE, essas contribuições auxiliam na compreensão dos desafios da legitimação dos PEs (Figura 3). Elas ajudam a cada ator da EE, qualquer que seja sua posição ou papel (instituição, quem aprende, mentor,

\footnotetext{
10 A autorização (ex.: em relação a diretivas institucionais, nacionais ou internacionais), a racionalização (instrumental - utilidade - ou teórica - referência à ordem natural das coisas), a moralização (que vem de um sistema de valores dominando o que nós queremos ver legitimado) e a mitopoiesis (legitimação implícita feita por objetos de narrativa - discurso).
} 
professor, coach, etc.), a compreender completamente a atividade ou projeto em questão e perceber os elementos com os quais os PEs podem ser legitimados.

\begin{tabular}{|c|c|}
\hline Naturalizando-se o passado & $\begin{array}{c}\text { A EE não contradiz a educação: ela usa } \\
\text { ideias, constructos e métodos considerados } \\
\text { legitimados (uso de diferentes campos de } \\
\text { conhecimento para construir essa } \\
\text { legitimidade). }\end{array}$ \\
\hline $\begin{array}{l}\text { Normalizando-se novos } \\
\text { significados }\end{array}$ & $\begin{array}{l}\text { A EE sugere a modificação da imagem } \\
\text { tradicional do professor convidando-o a } \\
\text { desempenhar novos papéis e ocupar } \\
\text { novas posições. }\end{array}$ \\
\hline $\begin{array}{l}\text { Alterando-se referências } \\
\text { de identidade }\end{array}$ & $\begin{array}{l}\text { A EE convida-nos a definir novas } \\
\text { referências de identidade (modelos de papel } \\
\text { empreendedor). }\end{array}$ \\
\hline Conectando-se com o ambiente institucional & $\begin{array}{l}\text { A EE, em essência integrada à instituição de } \\
\text { ensino, leva a definir ou até mesmo limitar } \\
\text { as ações e papéis dos professores. }\end{array}$ \\
\hline Autoridade de referência & $\begin{array}{l}\text { A EE legitima um ator por via do papel que } \\
\text { ele assume, em conexão com autoridades, } \\
\text { como pesquisadores, associações etc. }\end{array}$ \\
\hline
\end{tabular}

Figura 3: Desafios da legitimação dos PEs

Fonte: Adaptado de Lindströma (2016)

Segundo as ideias de Tyler e Lind (1992), a legitimidade deve ser ligada ao fato de que as decisões tomadas pelos PEs (escolha de conteúdo, atividades e métodos de ensino), ou de que os procedimentos que levaram a essas decisões, são pessoalmente favoráveis aos atores envolvidos. Em outras palavras, a legitimidade é atribuída quando as necessidades dos atores são atendidas.

Em relação às necessidades e legitimidade institucionais, a instituição é o garantidor da educação oferecida a seus estudantes. Isso assegura que, para realizar a educação corretamente, ela proveja professores de alto gabarito. A qualidade dos professores é avaliada em comparação com qualquer outro que já cumpriu com as mesmas incumbências na educação, seja em termos de método científico na produção de conhecimento, seja em termos de métodos pedagógicos. A instituição também usa essa abordagem mimética no recrutamento de novos professores. Para responder a essas necessidades segundo uma abordagem institucional hierárquica, o PE deve mostrar seu nível de expertise em 
docência/ciências da educação e o valor cientificamente provado das soluções pedagógicas que usa. Os professores devem também justificarem a natureza científica do conhecimento empreendedor que querem transmitir. Em outro nível, o desenvolvimento de projetos empreendedores e redes de relação profissional destaca a instituição que dá suporte a esses projetos. Os PEs respondem a essa necessidade contextual com uma abordagem de baixo para cima (bottom-up, em termos hierárquicos) que lhes permite fazerem mudanças nas atividades e disciplinas oferecidas pela instituição.

As expectativas e legitimidade dos pares faz com que a participação de pares em um projeto transdisciplinar de empreendedorismo, que é aberto externamente, requeira atenção a múltiplos aspectos e o uso engenhoso da expertise. O primeiro requisito é de natureza simbólica, com a tradicional polaridade entre instituição de ensino e negócio. Usando sua expertise em empreendedorismo, os PEs precisam mostrar que o conhecimento e as atividades que oferecem são úteis para a profissionalização dos estudantes e para a criação de valores de diferentes tipos. Nessa abordagem transdisciplinar, os pares são defensores de seu campo de conhecimento e de seus métodos de ensino. Esperam ser valorizados e reconhecidos quanto à identidade profissional de trabalhadores de uma prática legalizada, contabilistas ou projetistas. A expertise educacional e o valor científico do conhecimento aproveitado pela EE permitem aos PEs ganharem legitimidade dos pares por mimetismo e por reconhecimento de procedimentos que são coerentes com o que sabem.

Já em relação às expectativas dos stakeholders externos e legitimidade, podem ser eles empreendedores, instituições ou empresas operando no mundo real, os stakeholders externos focam, acima de tudo, em iniciativas para fazerem a estrutura durar ou crescer. Nem todos eles estão abertos a se envolverem em um projeto educacional, até mesmo se tal projeto visar a treinar seus empregados ou parceiros futuros. Para ampliar o interesse por seus projetos, os PEs devem desenvolver um capital cultural que os leve a compreenderem as necessidades dos stakeholders, que thes permita tornar compreendidas suas próprias necessidades. Para fazê-lo, vão usar sua expertise em empreendedorismo, incluindo conhecimentos e práticas. Eles mostrarão que essa expertise em EE permite aos estudantes aproximarem-se do que os empreendedores sabem em termos de comportamento e estado de espírito, que o projeto é legitimado porque 
permite aos empreendedores serem treinados à imagem dos empreendedores que podem encontrar no dia a dia.

Sobre o quesito necessidades e legitimidade dos estudantes, eles ocupam o centro da iniciativa de ensino e têm muitas necessidades, como, por exemplo, a da busca pela autonomia para obterem boas notas. Usando sua expertise em educação e EE, os PEs poderão adaptar seus discursos e práticas segundo os resultados pedagógicos que desejarem, que podem variar de aumentar a consciência sobre o empreendedorismo à incubação de negócios. Os estudantes também esperam que o ensino lhes dê o conhecimento e as habilidades úteis que procuram. A expertise dos PEs em empreendedorismo lhes possibilita oferecerem informações e atividades autênticas que preparem os estudantes para o mundo real. A legitimidade será obtida comparando-se 0 conhecimento e o comportamento com a experimentação em situações reais.

Adicionalmente, os estudantes esperam ser apoiados e avaliados de um modo equilibrado e justo. A expertise em educação e EE deveria possibilitar aos professores apresentarem suas abordagens de modo claro, destacando os elementos que serão avaliados e suas respectivas importâncias.

Necessidades do professor e legitimidade. Os PEs, como todos os professores, querem ganhar reconhecimento e terem sucesso profissional. A relativa novidade do campo e a falta de treinamentos inicial e contínuo podem levantar questões de legitimidade para os próprios PEs com relação a seus trabalhos e a suas situações. Para construir a expertise, os PEs devem combinar a sala de aula com o mundo exterior. Em contato com stakeholders externos e especialistas, eles desenvolvem suas redes de relações, seus conhecimentos e prática profissional (ex.: participando de treinamentos). Eles também aproveitam o feedback de diferentes pessoas ao longo do tempo sobre as atividades conduzidas por eles ou pelos estudantes.

A congruência percebida com o modelo empreendedor produzido pelas interações com essas pessoas permite aos PEs consolidarem seus próprios sensos de legitimidade na realização de suas funções. Em outras palavras, eles adotam uma abordagem empreendedora intrinsicamente proativa para se desenvolverem profissionalmente. 


\section{CONCLUSÃO}

Os modelos de ensino na EE são ainda experimentais no sentido de que estão constantemente tentando assegurarem seus fundamentos e se adaptarem a diferentes audiências e contextos. Certos conteúdos e práticas são vistos como legítimos, outros não. Mais trabalho é necessário para gerar clareza e estabelecer prova científica em relação a essas questões (Fayolle et al., 2016). Até mesmo o status de professor pode provocar tensões quanto à legitimidade da posição de professor. Grimmett et al. (2009) destacam a situação do professor-pesquisador na EE buscando legitimidade e que, por isomorfismo mimético, este adota valores científicos de sua instituição e de pares de outros campos do conhecimento (Sanders, \& Harrison, 2008). Conformando-se a tais valores, os professores arriscam esquecer as raízes ontológicas de suas práticas. $O$ desafio é conciliar as orientações e tradições de pesquisa da universidade com o pragmatismo e as práticas contingentes específicas do campo da EE. Essas práticas devem ser mais compreendidas com pesquisas e ganhar mais familiaridade com as práticas identificadas pelos empreendedores na realidade de suas atividades.

O objetivo conativo da EE é desenvolver proximidade entre o que é ensinado e o que é realmente feito no mundo dos negócios (Seikkula-Leino et al., 2015) para possibilitar aos estudantes agirem de modo pertinente. A EE então ganha legitimidade dos atores nesse ambiente, mas, vista da torre de marfim da universidade, a transversalidade da EE e a busca por constante ajustamento a um ambiente ambíguo impedem que legitimidade suficiente seja adquirida. Naturalmente, o mesmo ocorre para os professores. Não obstante, a partir do trabalho em equipes multidisciplinares, o desenvolvimento de redes de relação (interna e/ou externa) possibilita que todos os conhecimentos e habilidades necessários sejam cobertos e isso permite que os envolvidos tenham mobilidade entre especializações disciplinares e individuais que são muito pronunciadas.

A EE tem muitas razões para desenvolver tais equipes (Eide, \& Olsvik, 2017), além de contar com professores transdisciplinares e especialistas disciplinares capazes de aplicarem conhecimento em um contexto diferente.

A partir de tudo isso, os professores podem questionar a própria legitimidade para desempenharem um papel na EE (Eide, \& Olsvik, 2017). Os contatos que eles podem ter com os numerosos e diferentes stakeholders e uma análise comparativa com o comportamento "modelo" para um PE incentiva-os a se perguntarem sobre 
suas próprias práticas. Eles avançam para um processo reflexivo que destaca o que lhes está faltando, o que não necessariamente ocorre com um especialista de uma área "no conhecimento" tradicional. A prática reflexiva da EE pode, não obstante, possibilitar aos professores desenvolverem legitimidade, que podem ver refletida em suas próprias ações (Klossner, 2008).

Uma questão também emerge quanto à legitimidade institucional da EE (Gibb, 2011). A emergência vem de uma multiplicidade de chamados das classes políticas. Os PEs também devem desenvolver matérias de ensino que se alinhem com os valores de seus interlocutores nas universidades e escolas. Assim, os PEs podem desenvolver um discurso ad hoc para fazerem suas iniciativas serem bem recebidas e eventualmente organizarem mudanças, levando em conta a resistência encontrada (ex.: com ações de treinamento, comunidade de prática, etc.). Eles podem capitalizar a partir da legitimidade promovida pelos mais altos níveis da instituição fazendo conexões coerentes entre a EE e os objetivos da instituição, mas também identificando áreas possíveis de mudança na prática, no nível mais baixo das atividades da instituição, o mais próximo da realidade diária dos estudantes e de outros professores.

Definitivamente, a legitimidade da EE depende das interações entre instrutores legitimados e estudantes legitimados em um dado contexto que respeita certas normas coletivamente aceitas (ex.: aprendizagem baseada em problemas, aprender fazendo). Ela também depende do contexto e do objetivo da EE (ex.: elevar a consciência sobre o empreendedorismo versus incubação de novas empresas). Se certas práticas da EE são consideradas legítimas ou não, cabe aos pesquisadores fazerem a distinção.

A legitimidade, pensada apenas do ponto de vista das relações bilaterais de cada um dos atores, é difícil de ser obtida porque falta a percepção do todo do que é oferecido pela EE. Ver o todo implica avançar para uma dinâmica de relações multilaterais no contexto da EE e em um prazo preciso, o prazo dos atores-chave: os estudantes. Seguindo novamente o exemplo de um trabalhador de um hospital universitário (um médico), os PEs podem ser pessoas da prática, professores e pesquisadores. São elementos constituintes da legitimidade dos PEs: o seu grau de expertise, sua posição na instituição de ensino, o discurso que usam e seu posicionamento em relação a outros atores (estudantes, pares, colegas, stakeholders profissionais e institucionais). Enquanto a EE pode ser uma área de 
estudo e um campo de conhecimento emergentes, os fatores sociais e econômicos ligados ao empreendedorismo justificam o uso do melhor processo possível de profissionalização para os PEs.

\section{REFERÊNCIAS}

Aldrich, H. E., \& Fiol, C. M. (1994). Fools rush in? The institutional context of industry creation. Academy of Management Review, v. 19, n. 4, pp. 645-670.

Bourdieu, P. (1979). Les trois états du capital culturel. Actes de la recherche en sciences sociales, v. 30, n. 1, pp. 3-6.

Byrne, J., Fayolle, A., \& Toutain, O. (2014). Entrepreneurship education: What we know and what we need to know. In: Chell, E., \& Karataş-Özkan, M. (Eds.), Handbook of Research on Small Business and Entrepreneurship (pp. 261-288). Cheltenham: Edward Elgar Publishing.

Creese, A., Blackledge, A., \& Takhi, J. K. (2014). The ideal 'native speaker'teacher: Negotiating authenticity and legitimacy in the language classroom. The Modern Language Journal, v. 98, n. 4, pp. 937-951.

Dictionary, C. E. (2017). Consultado em: 22 mai. 2017.

Eddy Spicer, D. H. (2013). 'Soft Power' and the negotiation of legitimacy: Collective meaning making in a teacher team. Mind, Culture, and Activity, v. 20, n. 2, pp. 150169.

Eide, T. H., \& Olsvik, V. M. (2017). Qualitative case study of mini-company experiences in five European countries. ENRI working paper.

Fayolle, A. (2013). Personal views on the future of entrepreneurship education. Entrepreneurship \& Regional Development, v. 25, n. 7-8, pp. 692-701. 
Fayolle, A., Verzat, C., \& Wapshott, R. (2016). In quest of legitimacy: The theoretical and methodolog- ical foundations of entrepreneurship education research. International Small Business Journal, v. 34, n. 7, pp. 895-904.

George, M. (2013). Seeking legitimacy: The professionalization of life coaching. Sociological Inquiry, v. 83, n. 2, pp. 179-208.

Gibb, A. (2011). Concepts into practice: Meeting the challenge of development of entrepreneurship educators around an innovative paradigm: The case of the International Entrepreneurship Educators' Programme (ETEP). International Journal of Entrepreneurial Behavior \& Research, v. 17, n. 2, pp. 146-165.

Graça, J., Calheiros, M. M., \& Barata, M. C. (2013). Authority in the classroom: Adolescent autonomy, autonomy support, and teachers' legitimacy. European Journal of Psychology of Education, v. 28, n. 3, pp. 1065-1076.

Granovetter, M. (1983). The strength of weak ties: A network theory revisited. Sociological Theory, v. 1, pp. 201-233.

Grimmett, P. P., Fleming, R., \& Trotter, L. (2009). Legitimacy and identity in teacher education: A micro-political struggle constrained by macro-political pressures. AsiaPacific Journal of Teacher Education, v. 37, n. 1, pp. 5-26.

Günzel-Jensen, F., \& Robinson, S. (2017). Effectuation in the undergraduate classroom: Three barriers to entrepreneurial learning. Education + Training, v. 59, n. $7 / 8$, pp. $780-796$.

Hargreaves, A. (2000). Four ages of professionalism and professional learning. Teachers and Teaching: Theory and Practice, v. 6, n. 2, pp. 151-182.

Hargreaves, A., \& Fullan, M. (2012). Professional capital: Transforming teaching in every school. New York, NY: Teachers College Press. 
Hirschkorn, K. A. (2006). Exclusive versus everyday forms of professional knowledge: Legitimacy claims in conventional and alternative medicine. Sociology of Health \& Illness, v. 28, n. 5, pp. 533-557.

Katz, J. A. (2003). The chronology and intellectual trajectory of American entrepreneurship education: 1876-1999. Journal of business venturing, v. 18, n. 2, pp. 283-300.

Katz, J. A. (2008). Fully mature but not fully legitimate: A different perspective on the state of entrepre- neurship education. Journal of Small Business Management, v. 46, n. 4, pp. 550-566.

Klossner, J. (2008). The role of legitimation in the professional socialization of second-year under- graduate athletic training students. Journal of Athletic Training, v. 43 , n. 4 , pp. 379-385.

Kuratko, D. F. (2005). The emergence of entrepreneurship education: Development, trends, and chal- lenges. Entrepreneurship Theory and Practice, v. 29, n. 5, pp. 577-598.

Lindströma, S. (2016). 'An army of our own': Legitimating the professional position of HR through well-being at work. Scandinavian Journal of Management, v. 32, n. 4, pp. 189-196.

Maritz, A. (2017). Illuminating the black box of entrepreneurship education programmes: Part 2. Education \& Training, v. 59, n. 5, pp. 471-482.

Neck, H. M., \& Greene, P. G. (2011). Entrepreneurship education: Known worlds and new frontiers. Journal of Small Business Management, v. 49, n. 1, pp. 55-70.

Nielsen, A. (2016). Second career teachers and (mis) recognitions of professional identities. School Leadership \& Management, v. 36, n. 2, pp. 221-245.

Pedersen, J. S., \& Dobbin, F. (2006). In search of identity and legitimation: Bridging 
organizational culture and neoinstitutionalism. American Behavioral Scientist, v. 49, n. 7, pp. 897-907.

Peltonen, K. (2015). How can teachers' entrepreneurial competences be developed? A collaborative learning perspective. Education+ Training, v. 57, n. 5, pp. $492-511$.

Quirke, L. (2009). Legitimacy through alternate means: Schools without professionals in the private sector. British Journal of Sociology of Education, v. 30, n. 5, pp. 621-634.

Rae, D. (2017). Entrepreneurial learning: Peripherality and connectedness. International Journal of Entrepreneurial Behavior \& Research, v. 23, n. 3, pp. 486503.

Ruskovaara, E., \& Pihkala, T. (2015). Entrepreneurship education in schools: Empirical evidence on the teacher's role. The Journal of Educational Research, v. 108, n. 3, pp. 236-249.

Sanders, T., \& Harrison, S. (2008). Professional legitimacy claims in the multidisciplinary workplace: The case of heart failure care. Sociology of Health \& IIIness, v. 30, n. 2, pp. 289-308.

Seikkula-Leino, J., Satuvuori, T., Ruskovaara, E., \& Hannula, H. (2015). How do Finnish teacher edu- cators implement entrepreneurship education? Education+ Training, v. 57, n. 4, pp. 392-404.

Solomon, G. (2007). An examination of entrepreneurship education in the United States. Journal of Small Business and Enterprise Development, v. 14, n. 2, pp. 168182.

Tedmanson, D., Verduyn, K., Essers, C., \& Gartner, W. (2012). Critical perspectives in entrepreneur- ship research. Organization, v. 19, pp. 531-541.

Toutain, O., Fayolle, A., Pittaway, L., \& Politis, D. (2017). Role and impact of the 
environment on entrepreneurial learning. Entrepreneurship \& Regional Development, v. 29, n. 9/10, pp. 869-888. Taylor and Francis Online.

Tyler, T. R., \& Lind, E. A. (1992). A relational model of authority in groups. Advances in Experimental social Psychology, v. 25, pp. 115-191.

Wenger, E. (1998). Communities of practice: Learning, meaning, and identity. New York, NY: Cambridge University Press. 